\title{
DESEMPENHO DE PRÉ-TRATAMENTOS DE FOSFATO DE ZINCO DRY-IN-PLACE FRENTE À CONFORMAÇÃO MECÂNICA DE CHAPAS DE AÇOS BAIXO CARBONO*
}

Tiago Rafael Ferreira de Brito ${ }^{1}$ Célia Aparecida Lino dos Santos ${ }^{2}$

\section{Resumo}

O presente trabalho comparou o desempenho do fosfato de zinco e do microfosfato de zinco, ambos com tecnologia dry-in-place para verificação do comportamento destes revestimentos frente à conformação mecânica, por meio do ensaio de embutimento Erichsen, método Nakazima e curvas limite de conformação (CLC). Foram estudadas chapas de aço-carbono grau EM e grau EEP G4 eletrozincadas e fosfatizadas. As chapas foram fosfatizadas empregando-se dois banhos: fosfato de zinco e microfosfato de zinco, ambos com tecnologia dry-in-place. A caracterização da morfologia dos fosfatos estudados por microscopia eletrônica de varredura mostrou que as camadas de fosfato de zinco não apresentaram formação de cristais, quando aplicadas por roll coater e as análises por EDS comprovaram a presença do elemento fósforo. O ensaio de embutimento Erichsen somado aos resultados obtidos nas curvas CLC demonstraram que o microfosfato exibiu desempenho melhor em comparação ao fosfato. A diferença entre os dois tipos de fosfato foi mensurável e evidenciou que a tecnologia dry-in-place colaborou com a produção de camadas fosfatizadas adequadas para a lubrificação durante o processo de conformação mecânica.

Palavras-chave: Conformação mecânica; Fosfato de zinco; Microfosfato de zinco; Tecnologia dry-in-place.

\section{PERFORMANCE OF PRE-TREATMENT OF DRY-IN-PLACE ZINC PHOSPHATE ON THE MECHANICAL FORMING PROCESS OF LOW-CARBON STEELS \\ Abstract}

This study compared the performance of zinc phosphate and micro zinc phosphate, both using dry-in-place technology to verify the behavior of these coatings on mechanical forming, through means of the Erichsen cupping test, Nakazima method and forming limits curves (FLC). Zinc-plated and phosphatized EM and EEP G4-degree carbon steel plates were studied. The sheets were zinc-plated and phosphatized with two baths: zinc phosphate and micro zinc phosphate, both using dry-in-place technology. The characterization of the morphology of phosphates studied by scanning electron microscopy showed that the zinc phosphate layers showed no crystal formation when applied by roll coater and EDS analysis confirmed the presence of the element phosphorus. The Erichsen cupping test added to the FCL results showed micro zinc phosphate exhibited better performance compared to the zinc phosphate. The difference between the two types of phosphate was measured and showed that dry-in-place technology cooperating with suitable production for lubricating phosphated layer during the mechanical forming process.

Keywords: Forming; Zinc phosphate; Micro zinc phosphate; Dry-in-place technology.

1 Bacharel e Licenciada em Química, Doutora em Química (Físico-Química), Pesquisadora do Laboratório de Corrosão e Proteção e Professora do Centro de Ensino Tecnológico do Instituto de Pesquisas Tecnológicas do Estado de São Paulo - IPT, São Paulo, Brasil.

2 Engenheiro Químico, Mestre em Processos Industriais, Assistente Técnico da Armco do Brasil S.A., São Paulo, Brasil. 


\section{INTRODUÇÃO}

Os tratamentos industriais das superfícies metálicas apresentam, de maneira geral, três grandes vertentes: a proteção contra a corrosão, o acabamento visual (efeito decorativo) e a conformação mecânica. Esses tratamentos são amplamente utilizados sobre substratos de aço-carbono [1].

A conformação mecânica é uma operação industrial de grande importância porque transforma as superfícies metálicas dando-lhes novas dimensões ou formas geométricas. Para tanto, as superfícies a serem deformadas (superfícies metálicas) entram em contato com ferramentas (também metálicas) que ao aplicar uma dada força, executam as transformações necessárias. Neste momento, há o contato metal-metal que necessita de lubrificação para que a superfície conformada apresente boa qualidade e a ferramenta grande durabilidade [2].

As camadas fosfatizadas (destacadamente o fosfato de zinco), desenvolvidas desde o início do século XX e utilizadas com ênfase na conformação mecânica a partir da Segunda Guerra Mundial, exercem grande efeito por reter lubrificantes líquidos (óleos) ou sólidos (sabões), que auxiliam grandemente a lubrificação nos processos de conformação mecânica, reduzindo o atrito durante o contato metal-metal $[3,4]$.

Desde o final da década de 1980, há a preocupação de desenvolver processos de tratamentos superficiais não agressivos ao meio ambiente e, também, com melhor desempenho em relação aos praticados até então. Surge, neste período, o conceito de processo dry-in-place (processo sem lavagem/enxágue, também citados em inglês como no rinse) e dos processos livres de metais pesados, como por exemplo, processos livres de íons cromo, em contraposição aos processos vigentes [5].

Nos processos de fosfatização considerados tradicionais, uma grande quantidade de "borra" residual é formada. Esta borra, além de comprometer a eficiência do próprio banho de fosfato, necessita de filtração constante para a sua remoção, caso contrário, ela pode ser arrastada para a etapa de lavagem posterior, contaminandoa. Além disso, a etapa de lavagem necessita de tratamento específico para remoção da contaminação antes de ser dado o seu devido destino, seja ele o descarte ou o reaproveitamento da água no processo industrial.

Com a evolução do conceito de processos ambientalmente amigáveis, cresceu a necessidade da redução de geração de poluentes e resíduos, com isso fortaleceu-se a ideia de processo dry-in-place.

O processo de fosfatizaçao dry-in-place possui formulação específica para gerar menor quantidade de borra e realiza a secagem do banho sobre o substrato sem as etapas de enxágue, o que reduz o consumo de água e elimina a necessidade de tratamento da borra arrastada [5].

O presente trabalho tem por objetivo estudar o desempenho de diferentes camadas de fosfato de zinco com tecnologia dry-in-place (fosfato e microfosfato) frente à conformação mecânica dos aços-carbono graus EM e EEP - G4 laminados e eletrozincados. Os tratamentos superficiais foram realizados em uma linha industrial e as camadas fosfatizadas foram caracterizadas quanto à massa por unidade de área e morfologia (microscopia eletrônica de varredura, FEG-FIB). As propriedades de estampagem foram avaliadas por meio de ensaios Erichsen e pela elaboração de curvas limite de conformação (curvas CLC's). 


\section{MATERIAIS E MÉTODOS}

Os aços-carbono empregados foram ABNT NBR 5915/2008, graus EM e EEP - G4 [6].

Bobinas de aço EM e EEP G4, com espessuras de 0,6 mm, foram submetidas a uma sequência de processos para tratamento de suas superfícies em instalação industrial, a saber: desengraxe químico; enxágue; ativação ácida; enxágue; eletrodeposição da camada de zinco; aplicação de uma camada de fosfato de zinco ou microfosfato de zinco (processos dry-in-place) e, aplicação final de óleo protetivo comercial.

A eletrodeposição do zinco foi realizada a partir de um banho de zinco ácido, com densidade de corrente de $10 \mathrm{~A} / \mathrm{dm}^{2}$, a $45^{\circ} \mathrm{C}$ e velocidade de $40 \mathrm{~m} / \mathrm{min}$. A espessura das camadas eletrozincadas foram determinadas pelo método de emissão de raios $\mathrm{X}$.

Os banhos de fosfatização dry-in-place (sem enxágue) utilizados foram: fosfato de zinco e microfosfato de zinco aplicados via roll coater com secagem em estufa à $150^{\circ} \mathrm{C}$ imediatamente após a aplicação e sem lavagem intermediária.

As camadas fosfatizadas foram caracterizadas pelo método gravimétrico para a determinação da massa de fosfato por unidade de área e por microscopia eletrônica de varredura (MEV) em conjunto com a análise por dispersão de raios X (EDS) e corte transversal por meio de feixe de íons (FIB). Foram utilizados os microscópios FEG Quanta 400 e Quanta 3D FEG este com feixe duplo (dual beam).

A quantidade de óleo retido sobre os aços-carbono eletrozincados e fosfatizados também foi determinada pelo método gravimétrico e foi expressa em gramas por metro quadrado.

O ensaio Erichsen foi realizado conforme norma ABNT NBR 5902-1981 [7]. Empregou-se o equipamento do fabricante Roell + Korthaus KG com uma matriz de $27,0 \mathrm{~mm}$ com raio interno de $0,75 \mathrm{~mm}$ e o punção, de formato esférico, com $20,0 \mathrm{~mm}$ de diâmetro. Os corpos de prova utilizados possuíam $100,0 \mathrm{~mm} \mathrm{x}$ $150,0 \mathrm{~mm}$, o suficiente para fixação pelo prensa-chapas.

A velocidade do teste foi de $6,0 \mathrm{~mm} / \mathrm{min}$, a pressão de fixação do prensa-chapas foi de $10.000 \mathrm{kN}$, a temperatura ambiente de $23^{\circ} \mathrm{C}$. O teste foi conduzido até a ruptura do material.

Foram ensaiados três corpos de prova de cada condição testada e os resultados obtidos (Índice Erichsen e Pressão aplicada pela máquina) foram expressos pela média dos valores de três ensaios de cada condição.

O método Nakazima foi utilizado para obtenção das curvas limite de conformação dos aços estudados. Os ensaios foram divididos em 5 etapas: preparação dos corpos de prova, gravação da malha, estampagem dos corpos de prova, coleta de dados e construção das curvas.

\section{RESULTADOS E DISCUSSÃO}

\subsection{Caracterização das Camadas de Zinco Eletrodepositadas e das Camadas Fosfatizadas}

As camadas de zinco eletrodepositadas sobre os aços EM e EEP G4 apresentaram espessura média de $3,23 \mu \mathrm{m}$ e desvio padrão de $0,02 \mu \mathrm{m}$. 
Os valores de massa por unidade de área das camadas do fosfato e do microfosfato aplicadas sobre as bobinas de aço EM e EEP G4 eletrozincadas produzidas na linha industrial são apresentadas na Tabela 1.

Tabela 1 - Massa por unidade de área das camadas de fosfato e microfosfato dos materiais produzidos em linha industrial.

\begin{tabular}{c|c|c|c|c}
\hline \multirow{2}{*}{ Massa por unidade de área das camadas de fosfato de zinco e microfosfato de zinco $\left(\mathbf{g} / \mathbf{m}^{\mathbf{2}}\right)$} \\
\hline \multirow{2}{*}{ Corpo de prova } & \multicolumn{4}{|c}{ Condição } \\
\cline { 2 - 5 } & $\begin{array}{c}\text { Aço EM + } \\
\text { fosfato }\end{array}$ & $\begin{array}{c}\text { Aço EM + } \\
\text { microfosfato }\end{array}$ & $\begin{array}{c}\text { Aço EEP G4 + } \\
\text { fosfato }\end{array}$ & $\begin{array}{c}\text { Aço EEP G4 + } \\
\text { microfosfato }\end{array}$ \\
\hline Face 1 & 0,60 & 0,18 & 0,59 & 0,10 \\
\hline Face 2 & 0,59 & 0,16 & 0,60 & 0,09 \\
\hline Face 3 & 0,61 & 0,18 & 0,60 & 0,12 \\
\hline Contraface 1 & 0,65 & 0,16 & 0,61 & 0,10 \\
\hline Contraface 2 & 0,65 & 0,15 & 0,60 & 0,12 \\
\hline Contraface 3 & 0,63 & 0,16 & 0,61 & 0,10 \\
\hline Média & 0,62 & 0,17 & 0,60 & 0,11 \\
\hline Desvio & 0,03 & 0,01 & 0,01 & 0,01 \\
\hline
\end{tabular}

Destaca-se que a massa por unidade de área da camada do fosfato foi três vezes superior à massa de camada do microfosfato para o aço EM e seis vezes superior à massa da camada do microfosfato para o aço grau EEP G4, Tabela 1.

$\mathrm{Na}$ Tabela 2, apresentam-se os valores de massa por unidade de área de óleo retido sobre os aços sem e com fosfato e microfosfato produzidos na linha industrial.

Tabela 2 - Massa por unidade de área de óleo retido sobre os aços, aços com fosfato e aços com microfosfato produzidos na linha industrial.

\begin{tabular}{c|c|c|c|c|c|c}
\hline \multirow{2}{*}{ CP } & \multicolumn{7}{c}{ Camada de óleo protetivo $\left(\mathbf{g} / \mathbf{m}^{\mathbf{2}}\right)$} \\
\cline { 2 - 7 } & 1Aço EM & $\begin{array}{c}\text { Aço EEP } \\
\text { G4 }\end{array}$ & $\begin{array}{c}\text { Aço EM } \\
+ \\
\text { fosfato }\end{array}$ & $\begin{array}{c}\text { Aço EM + } \\
\text { microfosfato }\end{array}$ & $\begin{array}{c}\text { Aço EM + } \\
\text { fosfato }\end{array}$ & $\begin{array}{c}\text { Aço EEP G4 } \\
+ \\
\text { microfosfato }\end{array}$ \\
\hline Face 1 & 1,14 & 1,11 & 1,16 & 1,11 & 1,10 & 1,10 \\
\hline Face 2 & 1,13 & 1,12 & 1,16 & 1,11 & 1,10 & 1,10 \\
\hline Face 3 & 1,14 & 1,11 & 1,16 & 1,12 & 1,11 & 1,09 \\
\hline Contraface 1 & 1,16 & 1,15 & 1,14 & 1,14 & 1,12 & 1,08 \\
\hline Contraface 2 & 1,16 & 1,14 & 1,14 & 1,14 & 1,12 & 1,09 \\
\hline Contraface 3 & 1,15 & 1,15 & 1,14 & 1,13 & 1,12 & 1,10 \\
\hline Média & 1,15 & 1,13 & 1,15 & 1,13 & 1,11 & 1,09 \\
\hline Desvio & 0,02 & 0,02 & 0,01 & 0,01 & 0,01 & 0,01 \\
\hline
\end{tabular}

A quantidade de óleo retido, Tabela 2, foi de $1,15 \mathrm{~g} / \mathrm{m}^{2}$ para o aço EM e $1,13 \mathrm{~g} / \mathrm{m}^{2}$ para o aço EEP G4; $1,15 \mathrm{~g} / \mathrm{m}^{2}$ para o aço EM eletrozincado com fosfato, $1,13 \mathrm{~g} / \mathrm{m}^{2}$ para a condição aço EM eletrozincado com microfosfato; $1,11 \mathrm{~g} / \mathrm{m}^{2}$ para a condição aço EEP G4 eletrozincado com fosfato e $1,09 \mathrm{~g} / \mathrm{m}^{2}$ para a condição aço EEP G4 eletrozincado com microfosfato.

Houve, portanto, uma retenção de óleo ligeiramente menor sobre o aço "EEP G4" eletrozincado com fosfato e com microfosfato.

As imagens e análises por EDS das camadas eletrozincadas e fosfatizadas são apresentadas nas Figuras de 1 a 4. 


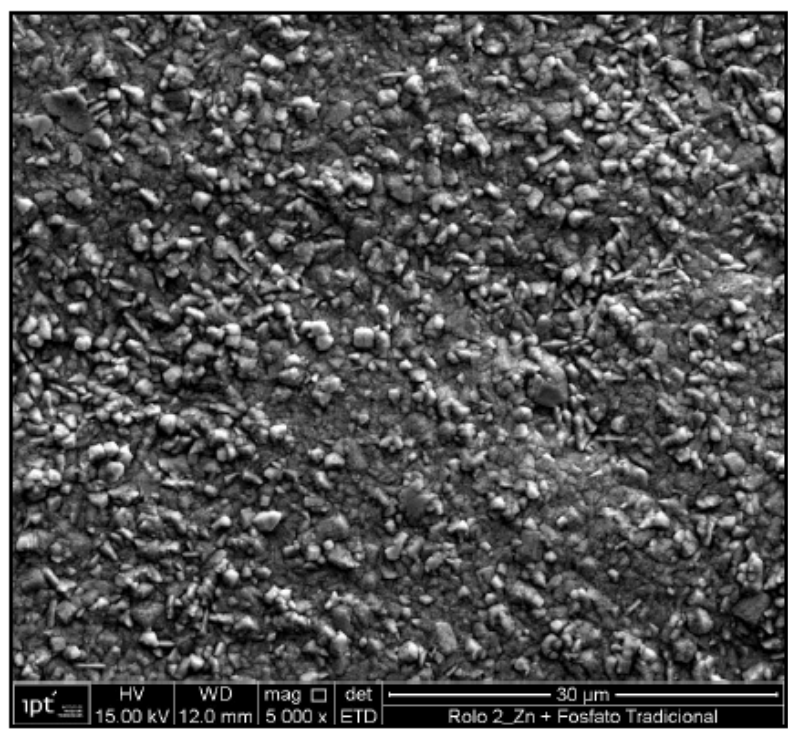

Figura 1 - Imagem de MEV do depósito de fosfato de zinco sobre camada eletrozincada.

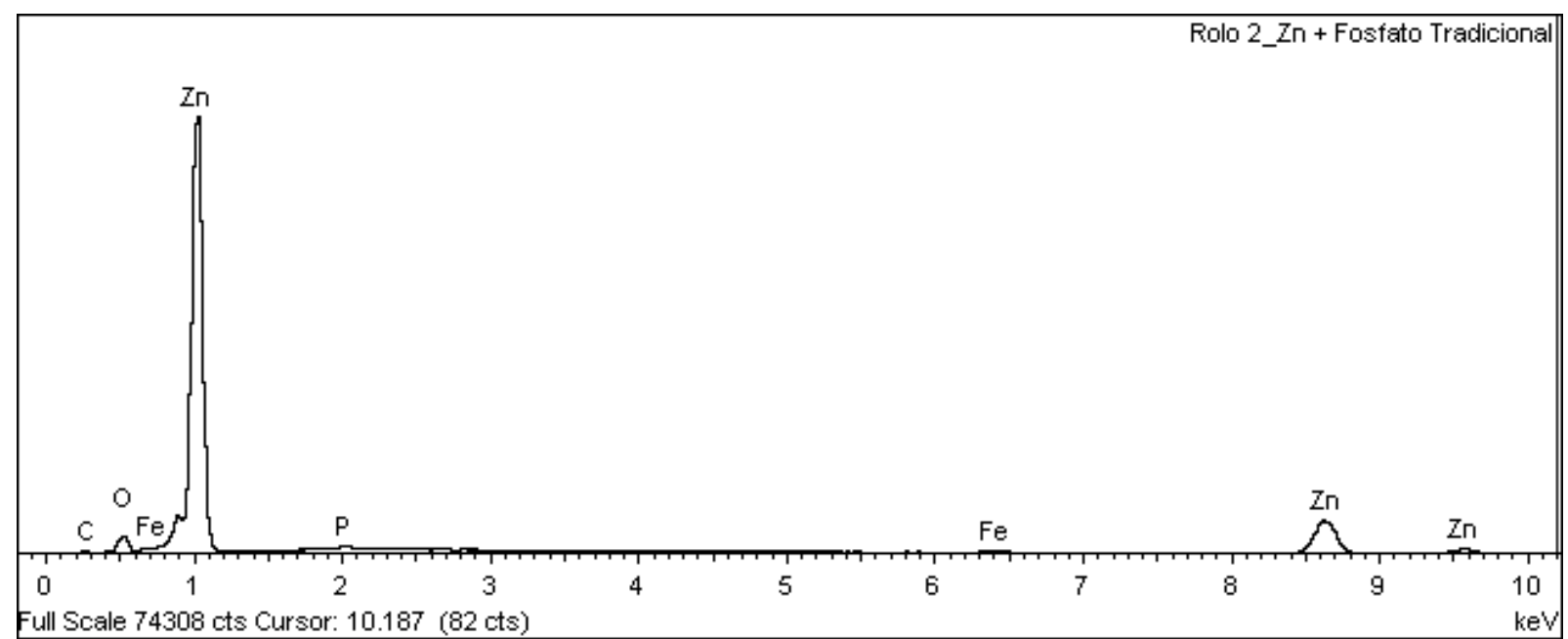

Figura 2 - Espectro de EDS para o revestimento de fosfato de zinco.

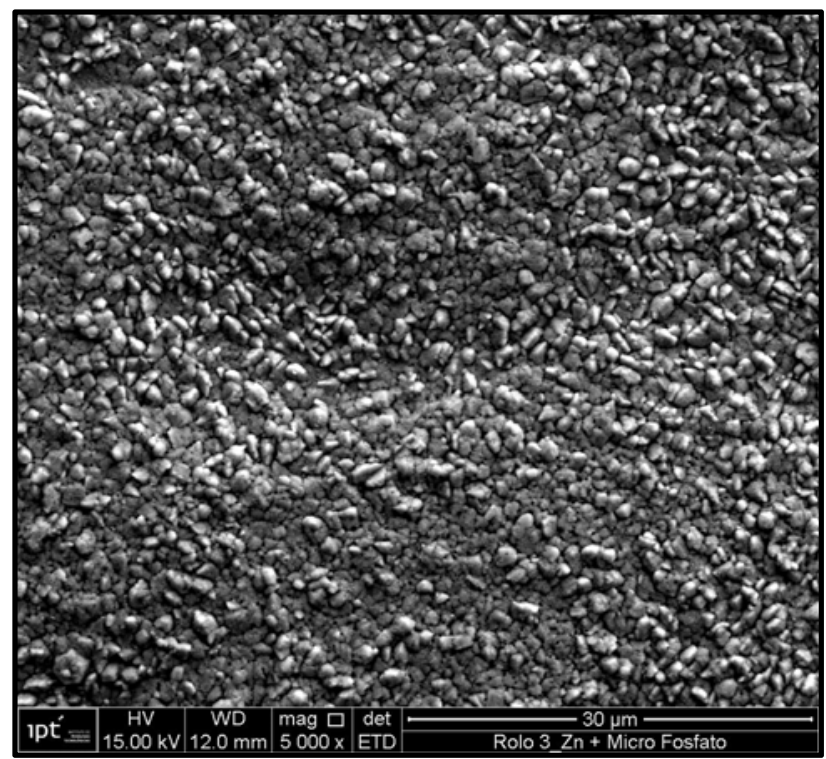

Figura 3 - Imagem de MEV-FEG do depósito de microfosfato de zinco sobre camada eletrozincada. 


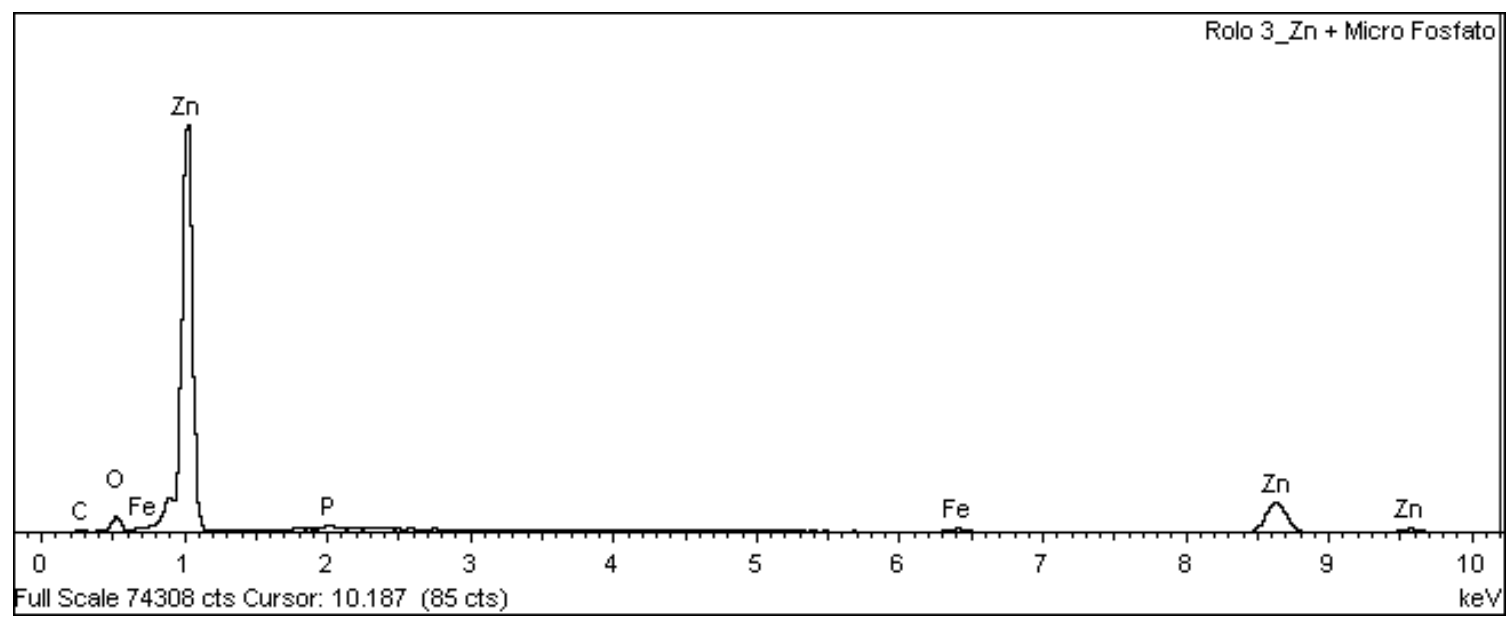

Figura 4 - Espectro de EDS para o revestimento de microfosfato de zinco.

Não foi possível observar pelas imagens de MEV-FEG a formação dos cristais de fosfato ou de microfosfato de zinco, Figuras 1 e 3 . Os cristais presentes nessas imagens são os grãos de zinco eletrodepositados.

No entanto, identificou-se por EDS a presença de fósforo na superfície dos aços eletrozincados e fosfatizados (fosfato e microfosfato), Figuras 2 e 4.

Cabe ressaltar que as análises de EDS não identificaram a presença do elemento fósforo sobre a superfície dos aços somente eletrozincados, ou seja, das amostras que não foram fosfatizadas.

A não visualização dos cristais de fosfato e a baixa intensidade do pico de fósforo das análises de EDS, Figuras 2 e 4, sugerem que as camadas de fosfato e microfosfato obtidas são amorfas e com baixa espessura.

Com o objetivo de mensurar a espessura das camadas de fosfato e de microfosfato, cortes transversais foram feitos com o auxílio de um microscópio eletrônico do tipo FEG com duplo feixe (FIB). O feixe de íons cortou as amostras, no sentido transversal, e foi possível identificar a camada de zinco eletrodepositada, a camada fosfatizada e a camada de platina depositada necessária para a realização do corte. As imagens dos cortes transversais estão apresentadas nas Figuras 6 e 7 .

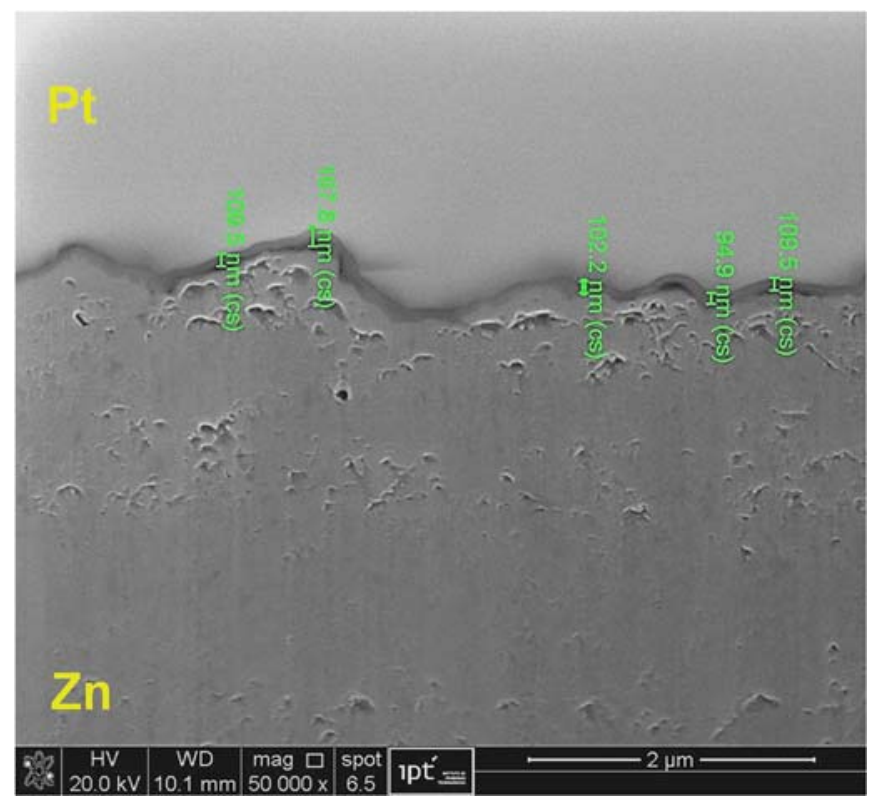

Figura 6 - Medidas da espessura da camada de fosfato de zinco sobre Imagem do corte transversal (FEG-FIB) da amostra eletrozincada com fosfato de zinco. 


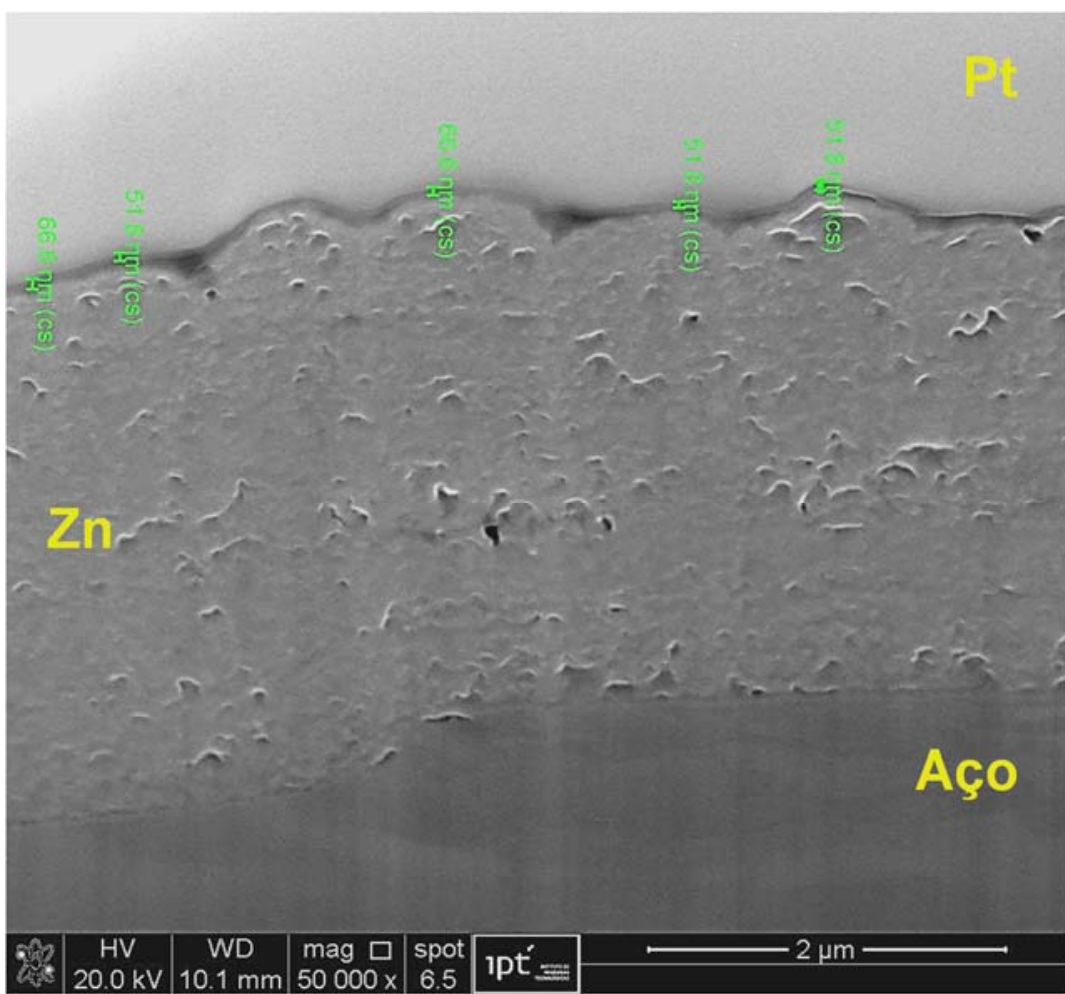

Figura 7 - Medidas da espessura da camada de fosfato de zinco sobre Imagem do corte transversal (FEG-FIB) da amostra eletrozincada com microfosfato de zinco.

A camada de fosfato de zinco mostrou-se contínua e as medidas de espessura variaram de $94,9 \mathrm{~nm}$ a $167,8 \mathrm{~nm}$, Figura 6.

A camada de microfosfato de zinco mostrou-se contínua e muito mais fina que a camada do fosfato de zinco. As medidas de espessura variaram de $51,8 \mathrm{~nm}$ a $66,6 \mathrm{~nm}$, Figura 7.

\subsection{Ensaios Mecânicos}

A seguir são apresentados os resultados dos ensaios de embutimento Erichsen. Nas Figuras 8 e 9, foram utilizadas as representações abaixo:

- Óleo - aço com óleo;

- Zn + óleo - aço eletrozincado com óleo;

- Zn + fosfato +óleo - aço eletrozincado com fosfato de zinco e com óleo;

- $\mathrm{Zn}+$ microfosfato +óleo - aço eletrozincado com microfosfato de zinco e com óleo.

Na Figura 8, os resultados das alturas de embutimento Erichsen para os aços EM e EEP G4, sem e com tratamento superficial, são apresentados. 


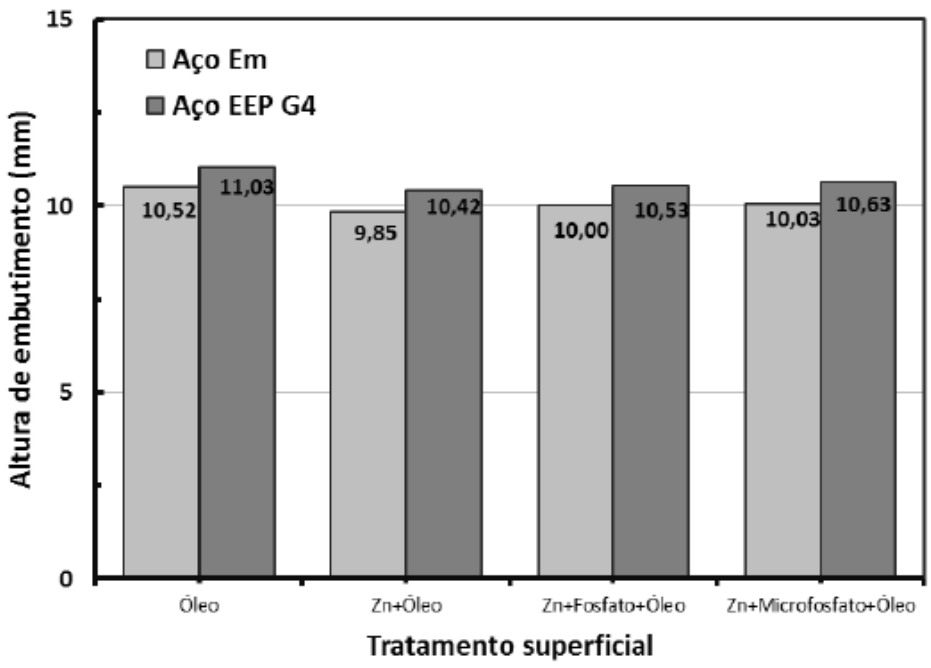

Figura 8 - Indice de embutimento Erichsen para os corpos de prova produzidos em linha industrial.

$\mathrm{Na}$ Figura 9, os resultados das pressões aplicadas durante os ensaios de embutimento Erichsen para os aços EM e EEP G4 sem e com tratamento superficial são apresentados.

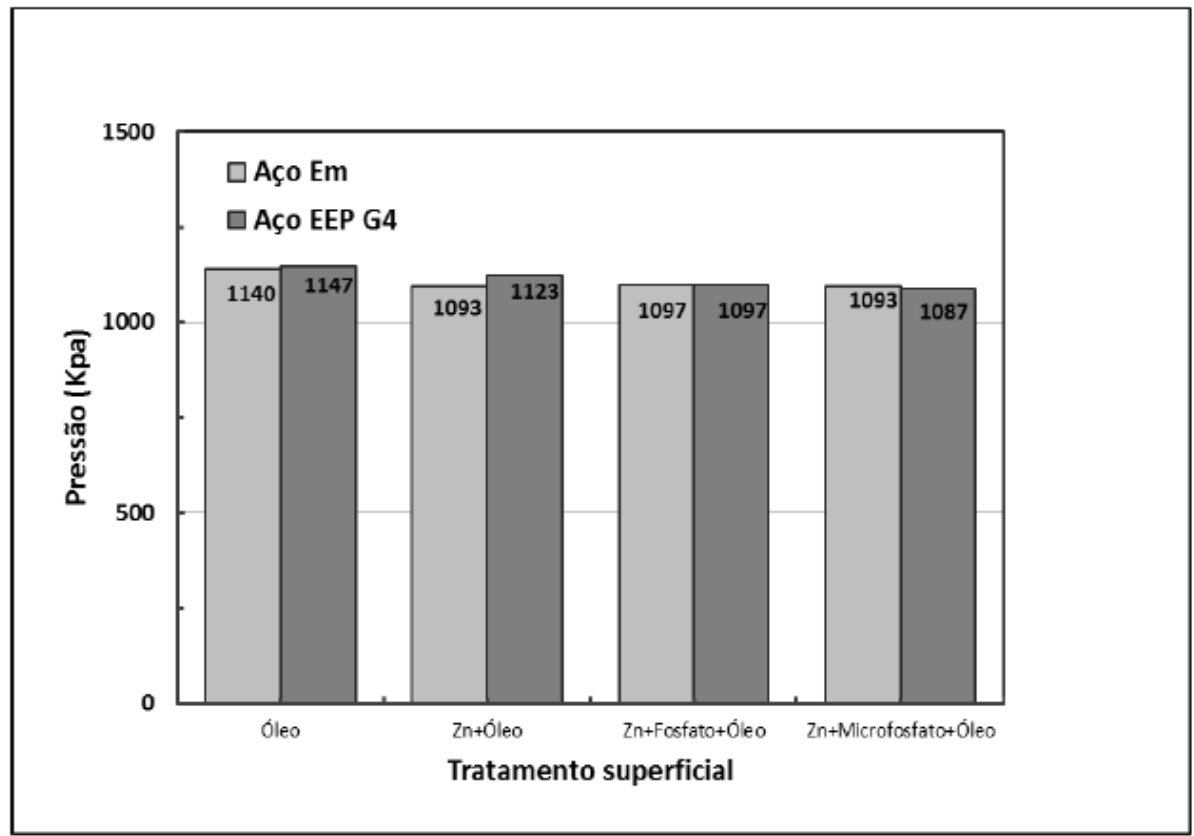

Figura 9 - Pressão exercida pela máquina de embutimento Erichsen para os corpos de prova produzidos em linha industrial.

Para ambos os aços estudados, Figura 8, os revestimentos de fosfato e microfosfato apresentam valores de altura de embutimento muito próximas e, percebe-se que foram eficientes devido à diminuição do valor de pressão exercida pela máquina quando da realização dos ensaios, Figura 9.

Com o objetivo de correlacionar os valores de altura de embutimento Erichsen e pressão exercida durante o ensaio de embutimento, construiu-se um gráfico, para ambos os aços, em que foram locados os valores resultantes da divisão das alturas 
de embutimento pelas forças exercidas e multiplicaram-se todos por cem. Esta normalização auxiliou na visualização do comportamento dos sistemas estudados.

$\mathrm{Na}$ Figura 10, observa-se que o revestimento de fosfato e de microfostato combinados com óleo melhoraram a relação altura de embutimento/pressão exercida, de maneira mais perceptível para o aço EEP G4, que respondeu melhor à influência da lubrificação quando comparado ao aço EM.

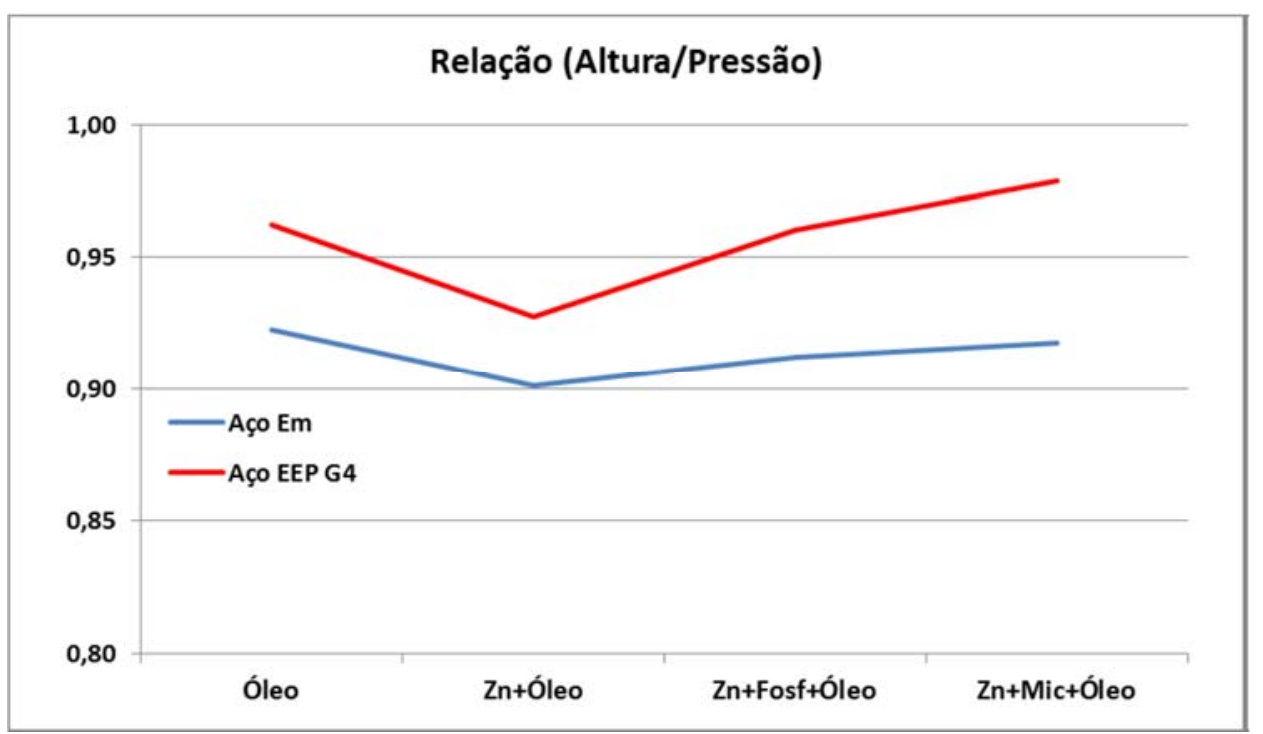

Figura 10 - Relação entre a altura de embutimento Erichsen e a pressão necessária para se alcançar a deformação. Relação para os corpos de prova produzidos em linha industrial.

As curvas limite de conformação foram realizadas segundo o método Nakazima. Nas Figuras 11 e 12, apresentam-se as curvas CLC's dos aços-carbono sem e com tratamento de eletrozincagem e fosfatização.

É possível notar que nas curvas do aço EEP G4, Figura 11, houve uma melhora promovida pelo microfosfato de zinco cujo valor de CLC zero foi de 0,29 , quando comparado às CLC's para o aço EM, Figura 12.

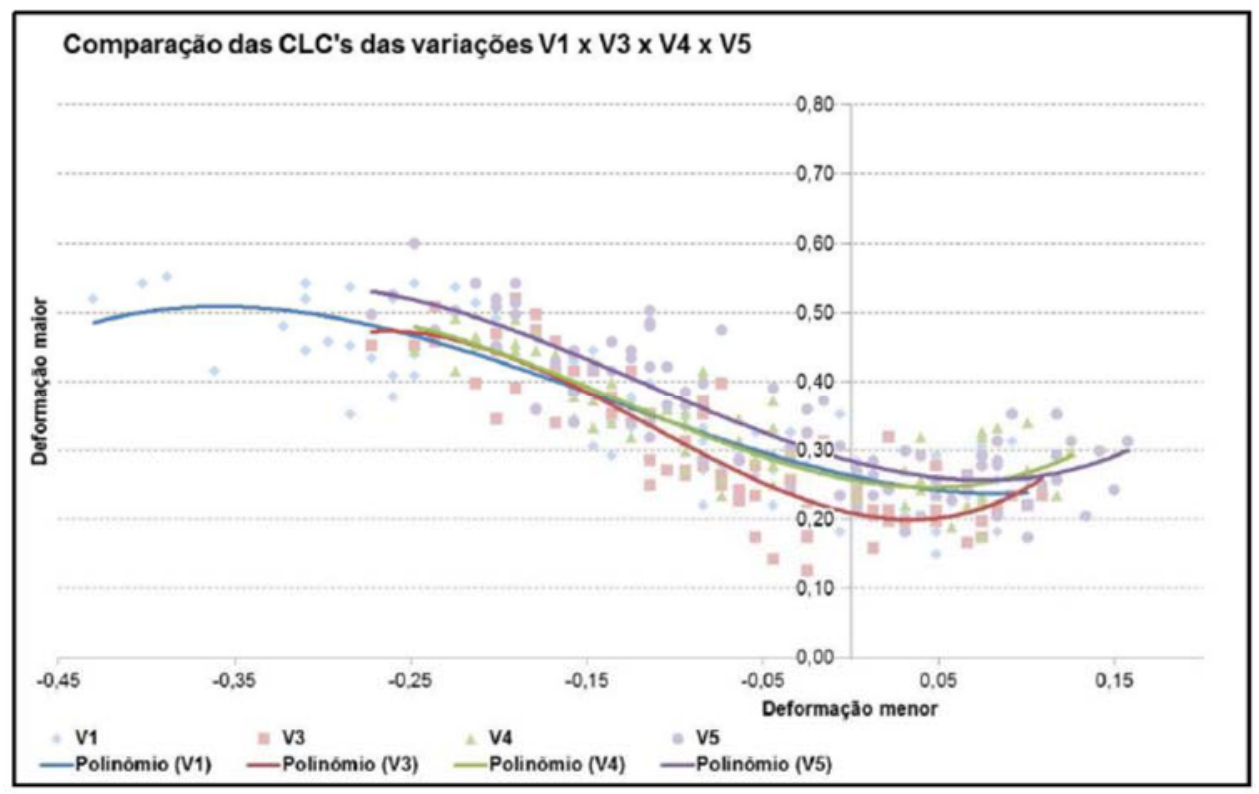

Figura 11 - Curva Limite de Conformação (CLC) do aço-carbono EEP G4 oleado (V1), aço-carbono EEP G4 + eletrozincagem + óleo (V3), aço-carbono EEP G4 + eletrozincagem + fosfato + óleo (V4), aço-carbono EEP G4 + eletrozincagem +microfosfato + óleo (V5). 


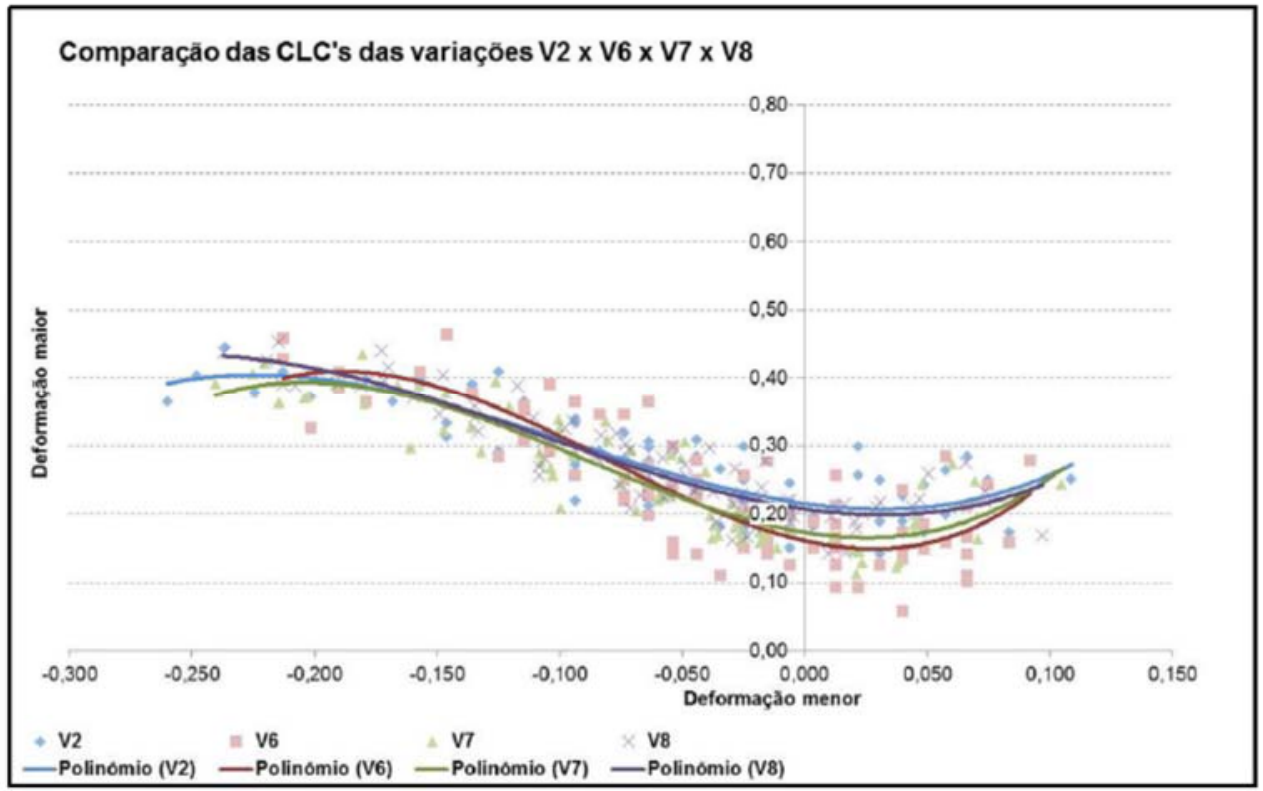

Figura 12 - Curva Limite de Conformação (CLC) do aço-carbono EM oleado (V2), aço-carbono EM + eletrozincagem + óleo (V6), aço-carbono EM + eletrozincagem + fosfato + óleo 4 (V7), aço-carbono EEP G4 + eletrozincagem + microfosfato + óleo (V8).

Este comportamento deve-se ao fato do aço EEP G4 possuir maior susceptibilidade à deformação e responder melhor às variações de lubrificação reduzindo o atrito metal/metal, promovido pelo contato entre o material e a ferramenta.

Os resultados das CLC's reafirmaram os resultados obtidos nos ensaios de embutimento Erichsen e mostraram que o microfosfato melhora, de fato, a lubrificação e auxilia o processo de estampagem.

\subsection{Discussão}

Duas das espessuras das camadas de zinco eletrodepositadas foram próximas a $3,0 \mu \mathrm{m}$, fato que era desejado para que houvesse uma espessura de zinco constante para todas as condições estudadas e se evitassem flutuações que poderiam influenciar os resultados dos ensaios mecânicos.

A retenção de óleo sobre todos os substratos sem e com tratamento superficial foi bastante semelhante entre eles e também não influenciou os ensaios mecânicos.

As camadas de fosfato e microfosfato produzidas na linha industrial (aplicados por roll coater) não apresentaram a formação de cristais de fosfato.

Nas análises feitas no MEV, embora não se tenha revelado a presença de cristais, os espectros gerados pelo EDS apontaram a presença de fósforo nas superfícies estudadas em pequena quantidade.

A presença de fosfato foi corroborada pela massa de camada de fosfato por unidade de área. Para o fosfato de zinco ela foi da ordem de $0,6 \mathrm{~g} / \mathrm{m}^{2}$ e para o microfosfato foi de $0,1 \mathrm{~g} / \mathrm{m}^{2}$.

As imagens dos cortes transversais, feitos por feixes de íons, evidenciaram que ambas as camadas de fosfatos são muito finas, a camada de fosfato de zinco ficou em torno de $100 \mathrm{~nm}$ e a de microfosfato, $50 \mathrm{~nm}$.

Apesar de serem finas, as camadas de fosfato estudadas influenciaram o comportamento dos aços EM e EEP G4 frente aos ensaios de embutimento Erichsen e curvas CLC's. 
O microfosfato de zinco auxiliou nos ensaios de conformação mecânica do aço EEP G4 e exibiu o maior valor de CLC zero e a melhor correlação entre altura de embutimento Erichsen e pressão exercida.

Cabe ressaltar que há pouca literatura sobre as novas tecnologias dos processos de fosfatização, mas os resultados experimentais deste trabalho permitem inferir que o processo sem enxágue poderá contribuir positivamente na conformação mecânica dos aços.

\section{CONCLUSÃO}

Apesar da massa por unidade de área da camada de microfosfato de zinco ter sido a menor, o microfosfato foi capaz de reduzir o atrito entre o material e a ferramenta (punção do ensaio Erichsen), contribuindo para melhorar a estampabilidade do aço EEP G4. O microfosfato com a tecnologia dry-in-place, ainda pouco utilizada na indústria nacional, mostrou-se eficiente frente aos ensaios de conformação mecânica e por não necessitar da etapa de enxágue após a sua aplicação, poder ser considerada uma tecnologia viável para a economia de água.

\section{Agradecimentos}

Os autores agradecem ao Centro Educacional da Fundação Salvador Arena (CEFSA), ao Centro de Educação Tecnológica (CET) - IPT e às empresas Armco do Brasil S.A. e Chemetall do Brasil Ltda.

\section{REFERÊNCIAS}

1 Landolt. D. Corrosion and surface chemistry of metals. In: Protection of engineering systems against corrosion, Lausanne: EPFL Press, 2007.

2 Bresciani Filho, E; Silva, I. B; Batalha, G. F.; Button, S. T. Conformação plástica dos metais. 1. ed. dig. São Paulo: EPUSP, 2011.

3 Panossian, Z., Santos, C. A. L. Fosfatização de metais ferrosos: Parte 1 - Histórico. Corrosão \& Proteção. 2006;3:22-23.

4 Panossian, Z., Santos, C. A. L. Fosfatização de metais ferrosos: Parte 20 - Póstratamento para conformação. Corrosão \& Proteção. 2010;7:24-26.

5 Wittke, W. J. The new age in pretreatment. Metal Finishing. 1989;aug:24-26.

6 ABNT - ASSOCIAÇÃO BRASILEIRA DE NORMAS TÉCNICAS. 1980. NBR 5902: determinação do índice de embutimento em chapas de aço pelo método Erichsen modificado. Rio de Janeiro. 5p.

7 ABNT - ASSOCIAÇÃO BRASILEIRA DE NORMAS TÉCNICAS. 1981. NBR 6673: produtos planos de aço - determinação das propriedades mecânicas à tração. Rio de Janeiro. $14 p$. 